\section{BRAZIULIAN JOURNAL}

OF MEDICAL AND BIOLOGICAL RESHARCH

www.bjournal.com.br
ISSN 0100-879X

Volume 43 (10) 914-1009 October 2010

BIOMEDICAL SCIENCES

AND

CLINICAL INVESTIGATION

Braz J Med Biol Res, October 2010, Volume 43(10) 1001-1009

doi: 10.1590/S0100-879X2010007500099

In vitro modulation of Bcl-2 levels in small cell lung cancer cells: effects on cell viability

A.O. Santos, J.P. Pereira, M.C. Pedroso de Lima, S. Simões and J.N. Moreira

The Brazilian Journal of Medical and Biological Research is partially financed by
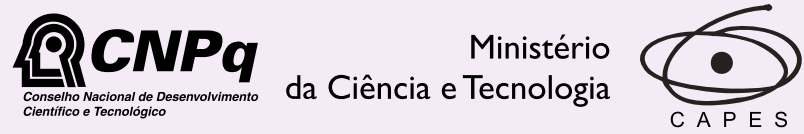

Ministério da Educação

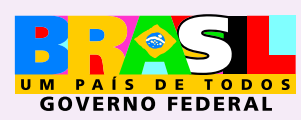

TFAPESP

Institutional Sponsors
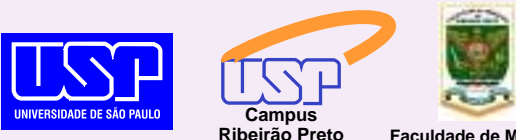

Ф SHIMADZU

GE Healthcare
Hotsite of proteomics metabolomics developped by:

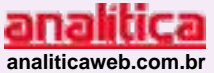

Thermo
SCIEN TIFIC 


\title{
In vitro modulation of Bcl-2 levels in small cell lung cancer cells: effects on cell viability
}

\author{
A.O. Santos ${ }^{1,2}$, J.P. Pereira1,2, M.C. Pedroso de Lima'2,3, \\ S. Simões ${ }^{1,2}$ and J.N. Moreira ${ }^{1,2}$
}

${ }^{1}$ Laboratory of Pharmaceutical Technology, Faculty of Pharmacy, ${ }^{2}$ Center for Neuroscience and Cell Biology, ${ }^{3}$ Department of Life Sciences, Faculty of Sciences and Technology, University of Coimbra, Coimbra, Portugal

\begin{abstract}
Small cell lung cancer (SCLC) is an aggressive disease, representing $15 \%$ of all cases of lung cancer, has high metastatic potential and low prognosis that urgently demands the development of novel therapeutic approaches. One of the proposed approaches has been the down-regulation of BCL2, with poorly clarified and controversial therapeutic value regarding SCLC. The use of anti-BCL2 small interfering RNA (siRNA) in SCLC has never been reported. The aim of the present study was to select and test the in vitro efficacy of anti-BCL2 siRNA sequences against the protein and mRNA levels of SCLC cells, and their effects on cytotoxicity and chemosensitization. Two anti-BCL2 siRNAs and the anti-BCL2 G3139 oligodeoxynucleotide (ODN) were evaluated in SCLC cells by the simultaneous determination of Bcl-2 and viability using a flow cytometry method recently developed by us in addition to Western blot, real-time reverse-transcription PCR, and cell growth after single and combined treatment with cisplatin. In contrast to previous reports about the use of ODN, a heterogeneous and up to $80 \%$ sequence-specific Bcl-2 protein knockdown was observed in the SW2, H2171 and H69 SCLC cell lines, although without significant sequencespecific reduction of cell viability, cell growth, or sensitization to cisplatin. Our results question previous data generated with antisense ODN and supporting the present concept of the therapeutic interest in BCL2 silencing per se in SCLC, and support the growing notion of the necessity of a multitargeting molecular approach for the treatment of cancer.
\end{abstract}

Key words: Small cell lung cancer; Gene silencing; Bcl-2, siRNA; Antisense ODN; Flow cytometry; Chemosensitization

\section{Introduction}

Small cell lung cancer (SCLC) is an aggressive and highly metastatic neuroendocrine histological subtype of lung cancer. The 5-year survival rate for patients diagnosed with invasive SCLC and bronchus cancer in the USA, from 1996 to 2004 , was $5.9 \%$ (1). This clearly demonstrates the need for the development of novel therapeutic approaches. The BCL2 gene is overexpressed in most SCLC specimens and cell lines, as opposed to other histological lung cancer types, a fact that has led to the hypothesis that it could be implicated in the pathogenesis of this tumor $(2,3)$. After the establishment of the oncogenic potential of Bcl-2 (4), its anti-apoptotic function further attracted the attention of researchers (5) because apoptosis deregulation has been implicated in cancer, therefore highlighting $B C L 2$ as a potential therapeutic target in a wide variety of tumors.

In the meantime, high expectations have been created regarding cancer therapy, with the possibility of targeting any single protein within a cell using gene silencing approaches. However, concerning SCLC, combined treatment of SCLC patients with G3139 oligodeoxynucleotide (ODN; oblimersen sodium) in phase II clinical trials did not improve any of the clinical parameters assessed, with insufficient BCL2 silencing being the reason suggested to explain the results obtained $(6,7)$. Although ODNs are still undergoing preclinical and clinical evaluation, other gene silencing molecules such as small interfering RNAs (siRNAs) are being used extensively in research both as powerful tools to decipher gene function and as promising therapeutic agents. The assessment of the therapeutic potential of anti-BCL2 gene silencing in SCLC has been restricted to the use of ODN (7-9), whereas no reports with siRNA are available. It is widely accepted that gene silencing therapies depend on the development of adequate nanocarriers to be used to achieve adequate intracellular delivery. This strategy is likely to profit from potent gene

Correspondence: J.N. Moreira, Faculty of Pharmacy and Center for Neuroscience and Cell Biology, University of Coimbra, Largo Marquês de Pombal, 3004-517 Coimbra, Portugal. E-mail: jmoreira@ff.uc.pt

Received February 25, 2010. Accepted September 13, 2010. Available online October 1, 2010. Published October $18,2010$. 
silencing molecules such as siRNA.

The objective of the present study was to select and validate the activity of an anti-BCL2 siRNA sequence for further use in the development of ligand-mediated targeted nanocarriers, in order to silence BCL2 in SCLC. In contrast to previous reports $(8,9)$ in which gene silencing was assessed in bulk cells by Western blot, a great advantage was obtained from a recently established flow cytometry procedure that simultaneously evaluates $\mathrm{Bcl}-2$ knockdown and viability in SCLC cells (10).

\section{Material and Methods}

\section{Material}

All salts and paraformaldehyde were purchased from Merck (Germany). 4-(2-Hydroxyethyl)-1-piperazine-ethanesulfonic acid (HEPES), sodium azide, N,N,N',N'-tetramethylethylenediamine, ammonium persulfate, digitonin, bovine serum albumin, RPMI 1640 with L-glutamine and without sodium bicarbonate (RPMI 1640), and penicillin-streptomycin solution $(10,000 \mathrm{U} / \mathrm{mL}$ and $10 \mathrm{mg} / \mathrm{mL}$, respectively) were from Sigma (Sigma-Aldrich Chemie $\mathrm{GmbH}$, Germany). 7-Aminoactinomycin D (7-AAD) and actinomycin D were from Fluka (Sigma-Aldrich). Fetal bovine serum (FBS) was from Gibco (Invitrogen S.A., Spain).

\section{Cell lines}

The human variant SCLC cell line SW2 was kindly provided by Drs. U. Zangemeister-Wittke and R. Stahel (University Hospital of Zurich, Switzerland). The classic $\mathrm{NCl}-\mathrm{H} 69$ and the variant $\mathrm{NCl}-\mathrm{NCl}-\mathrm{H} 2171$ human SCLC cell lines were from the American Type Culture Collection. Cells were cultured in RPMI 1640 supplemented with 10\% $(\mathrm{v} / \mathrm{v})$ heat-inactivated FBS, $1 \%(\mathrm{v} / \mathrm{v})$ penicillin-streptomycin solution, $10 \mathrm{mM} \mathrm{HEPES}$ and $0.2 \% \mathrm{NaHCO}_{3}$ and maintained at $37^{\circ} \mathrm{C}$ in a humidified atmosphere $(90 \%)$ containing $5 \%$ $\mathrm{CO}_{2}$. Cells were maintained in the exponential growth phase and periodically tested for mycoplasma contamination using the MycoAlert ${ }^{\circledR}$ mycoplasma detection kit from Cambrex Bio Science Verviers, Inc. (Belgium).

\section{ODN and SiRNA sequences}

All ODN sequences exhibit full length phosphorothioate modifications. The desalted forms of ODN G3139 (5'-TCTCCCAGCGTGCGCCAT-3') and G4126 (5'-TCTCC CAGCATGTGCCAT-3') were purchased from Microsynth (Balgach, Switzerland).

Two anti-BCL2 siRNA (siRNA $a$ and siRNA $b$ ) and a control non-targeting siRNA (siRNA $n t$ ) were purchased from Dharmacon Inc. (Lafayette, USA, and Perbio Science, Belgium) in the form of deprotected, annealed and desalted duplexes. Upon solubilization in ultrapure water or siRNA buffer (Dharmacon), the concentration of stock solutions of both ODNs and siRNAs was determined by absorbance at $260 \mathrm{~nm}$ using the appropriate extinction coefficient.

\section{Lipoplex preparation and cell transfection}

Lipoplexes were prepared with Oligofectamine ${ }^{\mathrm{TM}} \mathrm{Re}$ agent (Invitrogen). Oligofectamine (at $15 \mu \mathrm{L} / \mathrm{nmol}$ ODN or at $140 \mu \mathrm{L} / \mathrm{nmol}$ siRNA) was diluted 5 times in HEPES buffer saline (HBS) for $5 \mathrm{~min}$, mixed with ODN or siRNA solutions diluted in HBS (25 mM HEPES, $140 \mathrm{mM} \mathrm{NaCl}, \mathrm{pH}$ 7.4) and incubated for $20 \mathrm{~min}$. Complexes were added to cells in $1 / 5$ of the final volume followed, $4 \mathrm{~h}$ later, by the addition of RPMI 1640 supplemented with $30 \%$ FBS to achieve a final concentration per well of $10 \%(\mathrm{v} / \mathrm{v})$.

\section{Effect on cell growth of single and combined treatments with Bcl-2 silencing agents and cisplatin}

Sixteen-thousand viable cells/well in RPMI without phenol red, buffered with $25 \mathrm{mM} \mathrm{HEPES}$ and $2 \mathrm{~g} / \mathrm{L} \mathrm{NaHCO}_{3}$, were plated onto 96 -flat well plates in quadruplicate. Cells were treated for $4 \mathrm{~h}$ with a fixed concentration of the silencing agent or the corresponding control complexed with Oligofectamine. After $4 \mathrm{~h}$, cells were washed 3 times with RPMI without serum and further maintained in culture medium with $10 \%$ FBS. In the combined treatment schedules, cisplatin (Faulplatin ${ }^{\circledR}$, solution for iv injection, Mayne Pharma Ltd., Portugal), kindly donated by the University Hospital of Coimbra, was added $28 \mathrm{~h}$ after the first treatment. Ninety-six hours after the beginning of the experiment, relative cell growth inhibition was evaluated by the resazurin reduction method adapted from the AlamarBlue ${ }^{\mathrm{TM}}$ instructions (BioSource, Belgium). Briefly, plates were centrifuged, and 100 $\mu \mathrm{L}$ of the supernatant was replaced with $100 \mu \mathrm{L}$ of a $30 \%$ (v/v) solution of resazurin (Sigma) in RPMI 1640 without FBS from a recently prepared stock solution at $0.1 \mathrm{mg} / \mathrm{mL}$ of resazurin in Dulbecco's phosphate buffer saline (PBS; $1.4 \mathrm{mM} \mathrm{KH}_{2} \mathrm{PO}_{4}, 2.7 \mathrm{mM} \mathrm{KCl}, 4.3 \mathrm{mM} \mathrm{Na}_{2} \mathrm{HPO}_{4}, 137 \mathrm{mM}$ $\mathrm{NaCl}, \mathrm{pH} 7.4$ ). After incubation at $37^{\circ} \mathrm{C}$ for $2 \mathrm{~h}$, absorbance was measured at 540 and $630 \mathrm{~nm}$ in a plate spectrophotometer (Multiscan Ex, Thermo Labsystem, Finland). Percent resazurin reduction was calculated taking into consideration the extinction coefficients of resazurin at the aforementioned wavelengths. The results were normalized with respect to the untreated control wells (\% cell growth).

\section{BCL2 mRNA evaluation by real-time reverse-transcription $P C R$}

Cells were plated onto 6 -well $(0.25$ or 0.5 million cells/ well) or 12 -well plates ( 0.125 or 0.25 million cells/well) and transfected as described above with the indicated concentration of ODN or siRNA. At 24 h post-transfection, cells were harvested, washed with PBS and kept at $-80^{\circ} \mathrm{C}$.

Total RNA was isolated with the RNeasy ${ }^{\circledR}$ mini kit (QIAGEN GmbH, Germany), with in-column DNase digestion (QIAGEN GmbH) according to manufacturer instructions. The RiboGreen kit was used to quantify the isolated RNA solutions and 0.4 or $1 \mu \mathrm{g}$ RNA was reverse transcribed using the SuperScript ${ }^{\circledR}$ III First-strand Synthesis SuperMix (Invitrogen) according to the manufacturer protocol. Quan- 
titative real-time reverse-transcription PCR (qRT-PCR) was performed using the iQ SYBR Green Supermix (Bio-Rad Laboratories, USA), and the IQ5 PCR detection system/ iCycler ${ }^{\circledR}$ Thermal Cycler (Bio-Rad Laboratories). The optimized condition included an annealing and extension temperature of $55^{\circ} \mathrm{C}$ and primers at $300 \mathrm{nM}$. The following PCR primers were used: BCL2, sense 5'-CATGTGTGTGG AGAGCGTCAA-3', and antisense, 5'-GCCGGTTCAGG TACTCAGTCA-3', and $\beta-2-$ microglobulin $(B 2 M)$, sense 5'-GAGTATGCCTGCCGTGTG-3', and antisense, 5'-AAT CCAAATGCGGCATCT-3' (Microsynth, Switzerland). The melting curve protocol was started immediately after amplification to confirm the specificity of the reaction, which was further confirmed by agarose gel analysis. The percentage of BCL2 mRNA was calculated by the Pfaffl method (11), [E(target)dCt, target (calibrator sample - test sample)/ $\mathrm{E}$ (reference) ${ }^{\mathrm{dCt}}$, ref (calibrator sample - test sample) $] \times 100$, using $B 2 M$ as reference gene.

\section{Evaluation of $\mathrm{Bcl}-2$ protein level and cell viability}

Cells were plated and treated as described in the previous section. The $\mathrm{Bcl}-2$ protein level was measured by flow cytometry simultaneously with cell viability in a BD FACSCalibur ${ }^{\mathrm{TM}}$ system (BD Biosciences). Bcl-2 protein levels were determined with a phycoerythrin (PE)-conjugated mouse anti-human $\mathrm{Bcl}-2 \mathrm{mAb}$ (Bcl-2 mAb-PE, IgG1k, clone $\mathrm{Bcl}-2 / 100)$ and the corresponding $\mathrm{PE}$-conjugated isotype control (IgG1k, clone MOPC-21) were BD Pharmingen ${ }^{\mathrm{TM}}$ (BD Biosciences) (10).

Cell viability (\%) was calculated from the ratio between the percentage of viable treated cells and viable untreated cells. In each cell region (total cell population or viable cells), the specific geometric mean of the $\mathrm{Bcl}-2$ signal (\%) was normalized to the corresponding region of untreated cells. The specificity of the Bcl-2 signal in treated cells was also evaluated by considering the nonspecific signal, obtained upon staining with the mAb-PE isotype. The percentage of Bcl-2-silenced cells was calculated by subtracting the frequency histogram of viable untreated cells from that of viable treated cells and normalized to the total viable population. All subtractions were performed in histograms with the same number of events. The Bcl-2 signal in silenced cells (\%) was calculated from the ratio between the specific geometric mean of the Bcl-2 signal of silenced and untreated cells.

\section{Statistical analysis}

Data are reported as means \pm SEM. Differences between sequences were evaluated by matched or unmatched twoway analysis of variance (ANOVA), with Bonferroni's posttest analysis, or by the two-tailed unpaired $t$-test, depending on the study design, and significance levels were indicated with asterisks ( ${ }^{*} P<0.05,{ }^{* *} P<0.01$, and $\left.{ }^{* * *} P<0.001\right)$. Differences between treated and untreated cells were evaluated by two-tailed one sample $t$-test, and significance levels were indicated with the number sign (\#).

\section{Results}

\section{Bcl-2 down-regulation in SW2 SCLC cells is heterogeneous}

Under comparable conditions, the Bcl-2 signal of ODNtreated cells determined by flow cytometry was similar to the $\mathrm{Bcl}-2$ levels measured by Western blot when evaluated in the total cell population (data not shown). However, flow cytometry offers the additional possibility to evaluate Bcl2 protein levels and heterogeneity of expression in direct correlation with cell viability by creating regions in the FSC/7-AAD plot (10).

Instead of a small protein down-regulation (about $30 \%$ at 200 nM G3139 at 72 h; data not shown) in the "bulk" population, the single cell approach provided by flow cytometry showed a strong reduction in the Bcl-2 signal in a reduced percentage of viable cells. The subtraction of the histogram corresponding to untreated viable cells from the histogram of G3139-treated viable cells revealed that about $20 \%$ of

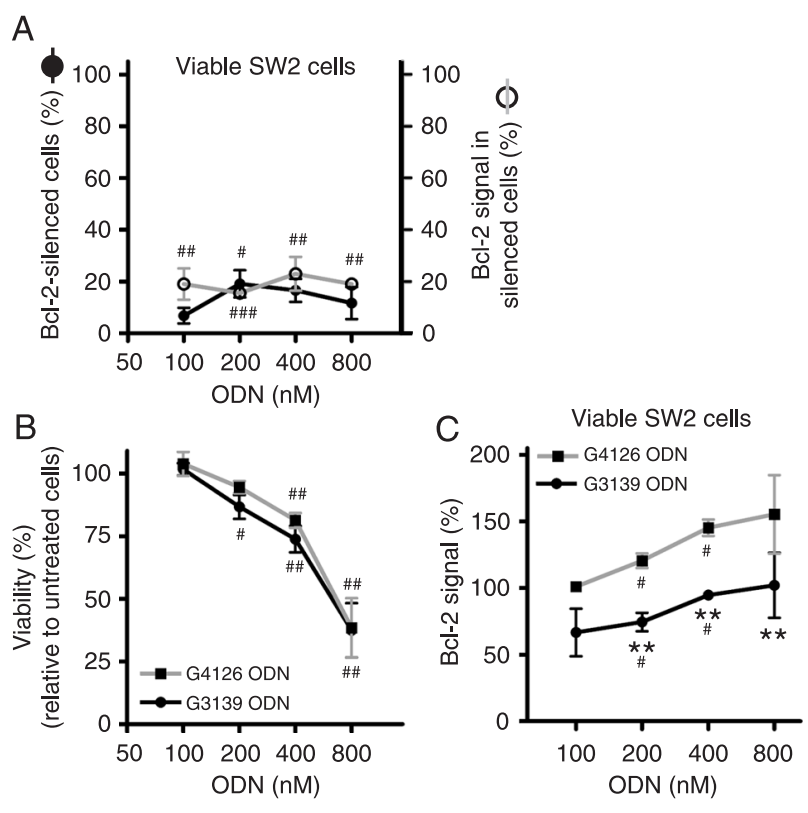

Figure 1. Effect of G3139 oligodeoxynucleotide (ODN) concentration on the $\mathrm{Bcl}-2$ protein signal and relative viability and on SW2 small cell lung cancer cells. Tumor cells were treated with different concentrations of G3139 ODN and the mismatch control G4126, as described in Material and Methods. The following parameters were assessed $72 \mathrm{~h}$ post-transfection: $A$, percentage of $\mathrm{Bcl}-2$-silenced cells along with their $\mathrm{Bcl}-2$ level; $B$, cell viability; $C$, the mean $\mathrm{Bcl}-2$ protein signal in viable cells. Percentages were determined relative to untreated cells. Each point represents the mean \pm SEM for $\mathrm{N}=3$ or $4 .{ }^{* *} \mathrm{P}<0.01$ represents the significance level of the difference between the effects of the anti-BCL2 sequence and the respective concentration of the respective control sequence (two-way ANOVA, Bonferroni's post-test). \#P $<0.05$, \# $\mathrm{P}<0.01$, and ${ }^{\# \#} \mathrm{P}<0.001$ represent the significance level of the effect of the tested sequences relative to untreated cells (one-sample $t$-test). 
the cells presented an $85 \% \mathrm{Bcl}-2$ knockdown (Figure 1A). This potent but cell percentagelimited $\mathrm{Bcl}-2$ down-regulation did not lead to a specific decrease of viability (Figure 1B), and nonspecific toxicity was observed with treatments at $400 \mathrm{nM}$. These findings at the protein level demonstrate the limited information provided by Western blot regarding the pattern of protein expression. Such heterogeneous Bcl-2 silencing might be correlated with different extents of complex internalization by SW2 cells, as observed with FITC-labeled nucleic acids at $400 \mathrm{nM}$, where only $36 \%$ of tumor cells had internalized complexes after $4 \mathrm{~h}$ of incubation (data not shown). The representation of the mean Bcl-2 signal demonstrated a significant sequence-specific effect of G3139 ODN on $\mathrm{Bcl}-2$ knockdown in a viable cell subpopulation (Figure 1C, $\mathrm{P}<0.0001$, matched two-way ANOVA). Consecutive transfections (at 0 and 24 h) with 100, 200 or 400 nM G3139 ODN did not result in significant improvements of sequence-specific Bcl-2 knockdown (data not shown).

These surprising results of incomplete and heterogeneous silencing of $\mathrm{Bcl}-2$ were further corroborated by transfections carried out with anti-BCL2 siRNA. At the optimized oligofectamine/siRNA ratio (4 times higher than the optimal proportion for ODN complexation in terms of charge ratio), one of the tested siRNA sequences (sequence $b$ ) produced a potent and sequence-specific Bcl-2 down-regulation in a dose-response manner $(P<0.0001)$, reaching a maximum of $63 \%$ in viable cells compared to untreated cells (Figure 2A). The Bcl-2-silencing potency of another siRNA sequence, siRNA $a$, was significantly lower than that of siRNA $b$ (data not shown). Moreover, no further improvements in Bcl-2 silencing were observed when the double-treatment schedule with siRNA $b$ was tested (data not shown).

The observation of the frequency histograms of the Bcl-2 signal clearly shows that knockdown of $\mathrm{Bcl}-2$ was heterogeneous also with siRNA (Figure 2B), and the overall improvement in Bcl-2 silencing, either by increasing the oligofectamine/siRNA ratio (data not shown), or siRNA concentration, always correlated with an increased percentage of silenced viable cells (up to $60 \%$, Figure $2 \mathrm{C})$. In the silenced cells, the $\mathrm{Bcl}-2$ signal reduction was between 76 and $82 \%$, regardless of siRNA concentration and percentage of silenced cells (Figure 2C).

The same optimized oligofectamine/siRNA $b$ ratio was further tested in $\mathrm{H} 2171$ and $\mathrm{H} 69$ SCLC cells, which exhibit lower and higher constitutive Bcl-2 levels than SW2 cells,
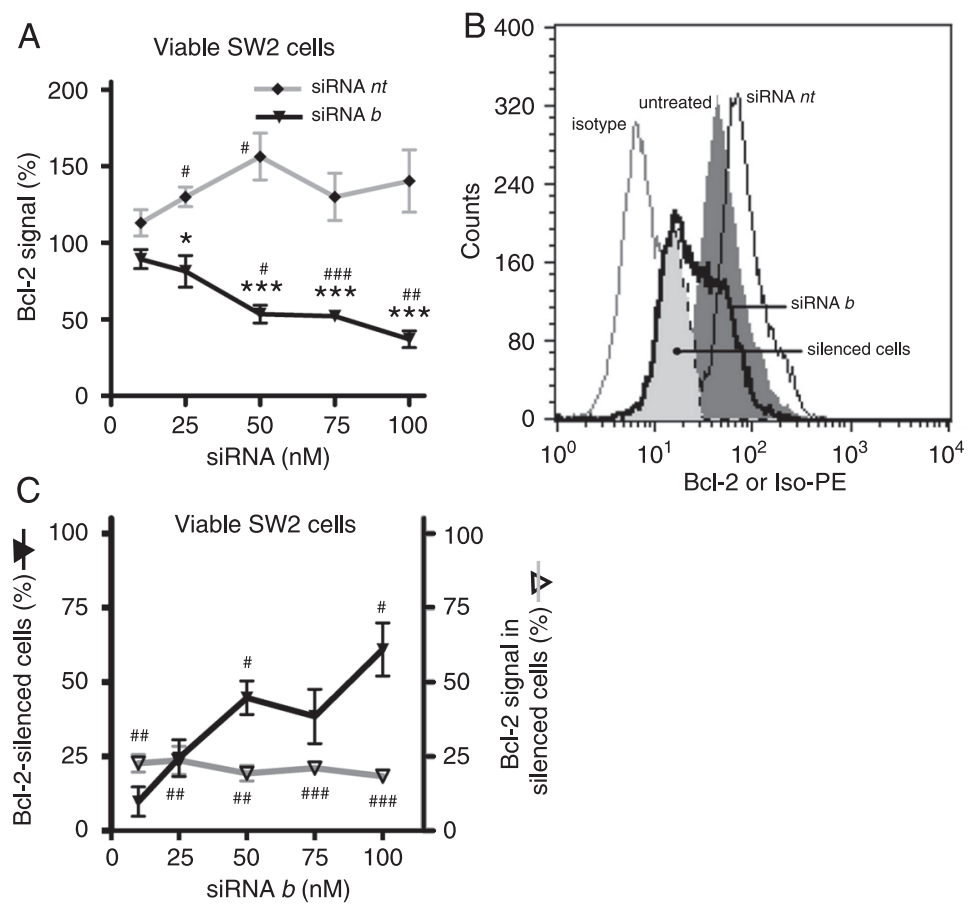

Figure 2. Effect of siRNA concentration on the relative Bcl-2 protein signal and percentage of $\mathrm{Bcl}-2$-silenced cells at the optimized oligofectamine/siRNA ratio in SW2 small cell lung cancer cells. Tumor cells were treated with different concentrations of siRNA complexed with oligofectamine at $140 \mu \mathrm{L} / \mathrm{nmol}$ siRNA, as described in Material and Methods. A, The mean Bcl-2 signal (\%) in viable SW2 cells was evaluated $72 \mathrm{~h}$ after the beginning of the experiment. $B$, Histograms of the Bcl-2 signal of viable siRNA-treated (at $50 \mathrm{nM}$ ) or untreated cells. $\mathrm{PE}=$ phycoerythrin. $C$, The area corresponding to 'silenced cells' results from the subtraction of the untreated cell histogram from the siRNA $b$-treated cell histogram. The percentage of silenced cells and of the Bcl-2 signal in these 'silenced cells' is represented for all tested concentrations of siRNA $b$. siRNA $=$ small interfering RNA. Each point represents the mean \pm SEM for $\mathrm{N}=3$ or 4. The difference in sequence effect was statistically significant under two-way ANOVA $(P<0.0001)$. ${ }^{*} P<0.05$ and ${ }^{* * *} P<0.001$ represent the significance level of the difference between the effects of sequence $b$ and the respective concentration of non-targeting ( $n t$ ) sequence (two-way ANOVA, Bonferroni's post-test). ${ }^{\mathrm{P}}<0.05,{ }^{\#} \mathrm{P}<0.01$, and ${ }^{\# \#} \mathrm{P}<0.001$ represent the significance level of the tested sequences relative to untreated cells (one sample $t$-test).

respectively. A partial $\mathrm{Bcl}-2$ signal reduction was observed in both cell lines, although to a lesser extent than in SW2 cells (Figure $3 \mathrm{~A}$ and $\mathrm{B}$ ). The difference in $\mathrm{Bcl}-2$ signal reduction between target and control sequences was statistically significant for both $\mathrm{H} 2171$ and $\mathrm{H} 69$ cells $(\mathrm{P}<0.0001$, two-way ANOVA), similar to that observed in SW2 cells.

\section{Effect of strong BCL2 silencing on cell viability and growth}

Interestingly, siRNA $b$ and siRNA nt exhibited a different effect on the viability of SW2 cells $(P<0.001$, two-way ANOVA). At 75 and $100 \mathrm{nM}$, corresponding to the best BCL2silencing conditions, and with which nonspecific toxicity was 
associated (evidenced from the incubation with siRNA $n t$ ), siRNA $b$ induced less reduction of cell viability than siRNA $n t$ (Figure 4A). The absence of the expected cytotoxicity of the anti-BCL2 sequence was also confirmed in the cell growth assay using resazurin reduction. At this level, however, the effect of the BCL2-targeting and non-targeting sequences was not significantly different (Figure 4B).

In agreement with that observed with SW2 cells, Bcl2 down-regulation did not lead to a reduction in viability of $\mathrm{H} 2171$ and $\mathrm{H} 69$ SCLC cells at $72 \mathrm{~h}$ post-transfection (Figure $4 \mathrm{C}$ and D).

\section{Bcl-2 mRNA down-regulation in SW2 SCLC cells}

To gain further insights into the cellular effects of ODN and siRNA transfection the BCL2 mRNA levels were measured by qRT-PCR in SW2 cells $24 \mathrm{~h}$ after the beginning of the experiment. A sequence-specific reduction of the BCL2 mRNA level was observed, reaching approximately $70 \%$ at
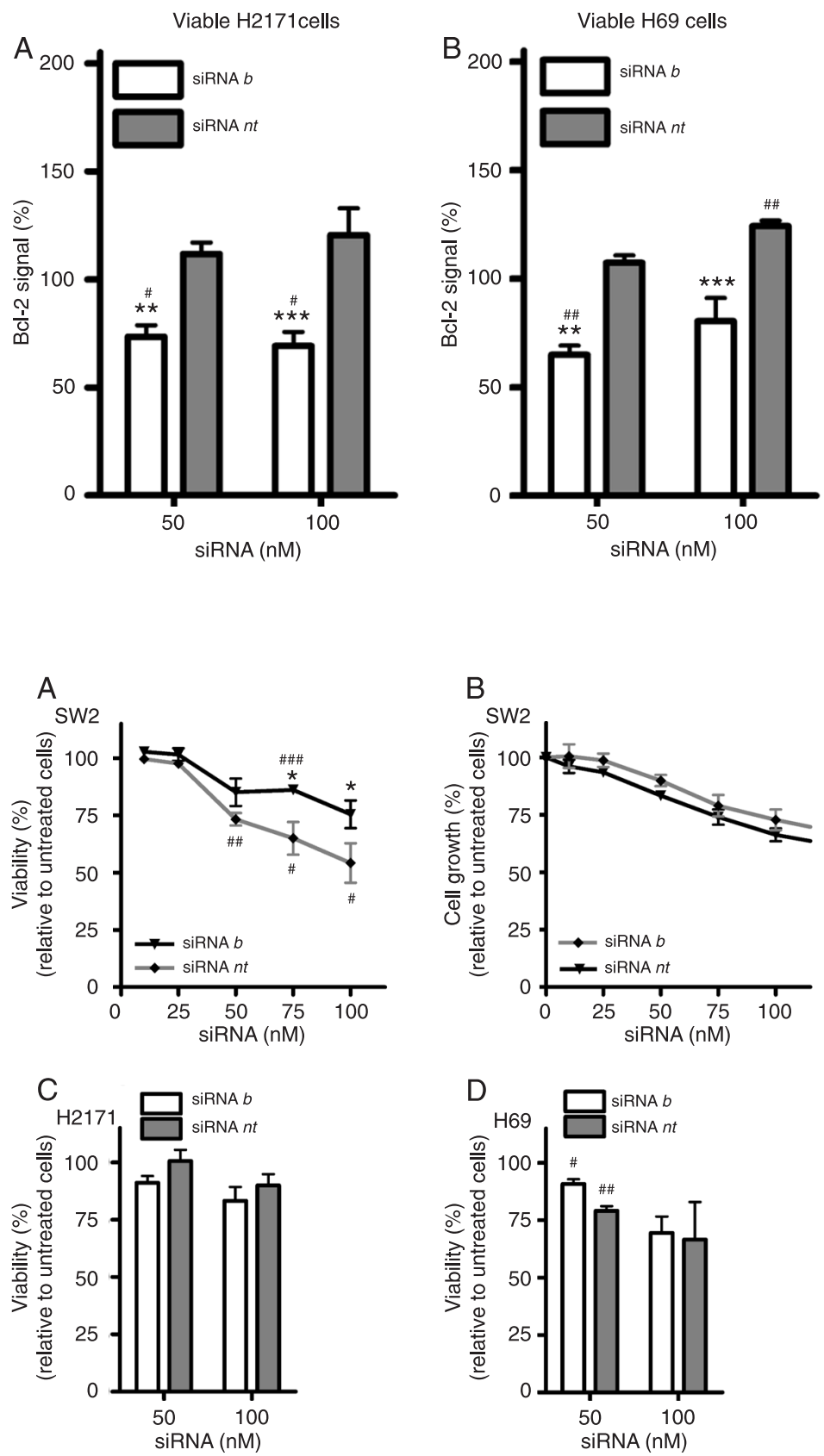

Figure 3. Effect of siRNA concentration on the relative $\mathrm{Bcl}-2$ protein signal in $\mathrm{H} 2171$ and $\mathrm{H} 69$ small cell lung cancer cells. Tumor cells were treated with different concentrations of siRNA complexed with oligofectamine at $140 \mu \mathrm{L} / \mathrm{nmol}$ siRNA, as described in Material and Methods. The mean relative $\mathrm{Bcl}-2$ signal of viable $\mathrm{H} 2171$ cells $(\mathrm{A})$ and of viable $\mathrm{H} 69$ (B) cells was evaluated at the same time after treatment. siRNA $=$ small interfering RNA. Each point represents the mean \pm SEM for $N=3$ or 4 . The difference in sequence effect was statistically significant in viable $\mathrm{H} 2171$ and $\mathrm{H} 69$ cells $(P<0.0001$, two-way ANOVA). ${ }^{* *} P<0.01$ and ${ }^{* * *} P<0.001$ represent the significance level of the difference between the effects of sequence $b$ and the respective concentration of non-targeting $(n t)$ sequence (twoway ANOVA, Bonferroni's post-test). ${ }^{\mathrm{P}}<0.05$ and $\# \#<0.01$ represent the significance level of the tested sequences relative to untreated cells (one sample $t$-test).

Figure 4. Effect of siRNA concentration on the viability and growth of small cell lung cancer cells. Tumor cells were treated with different concentrations of siRNA complexed with oligofectamine at $140 \mu \mathrm{L} /$ nmol siRNA, as described in Material and Methods. The viability of SW2 cells $(A)$ and cell growth (B) were assessed 72 and $96 \mathrm{~h}$ after the beginning of the experiment, respectively. Likewise, the viability of $\mathrm{H} 2171$ cells (C) and of $\mathrm{H} 69$ cells (D) was evaluated at $72 \mathrm{~h}$ post-transfection. siRNA $=$ small interfering RNA. Each point represents the mean \pm SEM for $N=3$. The difference in sequence effect was statistically significant $(P=0.0013$, two-way ANOVA) regarding both viability and growth $(P=$ 0.0018 ) of SW2 cells. ${ }^{*} P<0.05$ represents the significance level of the difference between the effects of sequence $b$ and the respective concentration of non-targeting ( $n t)$ sequence (two-way ANOVA, Bonferroni's post-test). ${ }^{\#} P<0.05,{ }^{\#} P<0.01$, and $\# \#$ P $<0.001$ represent the significance level of the difference of the tested sequences relative to untreated cells (one sample $t$-test). 
50 nM siRNA $b$ and 400 nM G3139 ODN (Figure 5).

\section{Increases of $\mathrm{Bcl}-2$ as a result of oligofectamine- mediated transfection of SW2 SCLC cells}

From the previous results, nonspecific sequence effects at the protein level were evident in viable cells when incubated with control sequences, as demonstrated by the increase of the $\mathrm{Bcl}-2$ signal with concentration. This increase was significant at 200 and 400 nM G4126 ODN (Figure 1C) and 25 and $50 \mathrm{nM}$ siRNA nt (Figure 2A). Conversely, a reduction of the $\mathrm{Bcl}-2$ signal was evident in the dead cell subpopulation compared with the same subpopulation of untreated cells, when treatments were carried out at the highest concentration of control ODN (data not shown). This nonspecific increase of $\mathrm{Bcl}-2$ in viable cells might contribute to masking the average reductions in $\mathrm{Bcl}-2$ signal in these cells compared to untreated cells. When assessment is

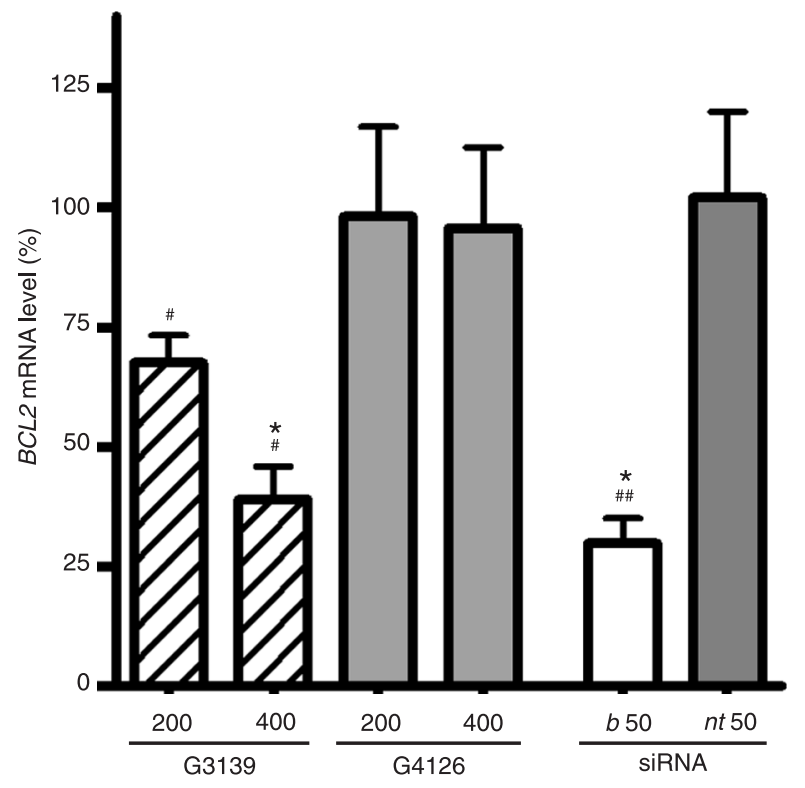

Figure 5. Effect of ODN and siRNA concentrations (in $\mathrm{nM}$ ) on the BCL2 mRNA level of SW2 small cell lung cancer cells. Tumor cells transfected with the indicated concentration of ODN $(15 \mu \mathrm{L}$ oligofectamine/nmol ODN) or siRNA ( $140 \mu \mathrm{L}$ oligofectamine/nmol siRNA) were harvested $24 \mathrm{~h}$ after the beginning of the experiment for mRNA evaluation by quantitative real-time PCR. ODN = oligodeoxynucleotide; siRNA = small interfering RNA. Data represent the mean \pm SEM for $N=3$. The difference in the effect of ODN sequence was statistically significant $(P=0.0398$, two-way ANOVA). ${ }^{*} P<0.05$ represents the significance level of the difference between the effects of sequences G3139 and G4126 (twoway ANOVA) or siRNA $b$ and non-targeting ( $n t$; unpaired $t$-test), at each respective concentration. $\# P<0.05$ and ${ }^{\#} P<0.01$ represent the significance level of the difference of the mean mRNA level of each treatment condition tested relative to untreated cells (one sample $t$-test). performed with methods like Western blot this nonspecific effect might not be noticed, conditioning the interpretation of the results.

\section{Assessment of inhibition of SW2 SCLC cell growth by a combination of BCL2 silencing and cisplatin treatment}

Although the BCL2-silencing approach was not deleterious to SCLC cells per se, it still could enhance the sensitivity of these tumor cells to cytotoxic drugs like cisplatin widely used in the treatment of SCLC patients. In this regard, the effect of the combined treatments with siRNA $b$ and cisplatin on cell growth was evaluated by the resazurin reduction assay. For this purpose, cells were treated with siRNA $b$ or nt under optimized silencing conditions ( $50 \mathrm{nM}$ siRNA and $140 \mu \mathrm{L}$ oligofectamine/nmol siRNA), followed by cisplatin $28 \mathrm{~h}$ after the first treatment. The combined treatment with siRNA $b$ and cisplatin was as toxic as cisplatin alone, whereas the combination of siRNA nt with cisplatin resulted in an even lower cytotoxicity than the one caused by the latter treatment (Figure 6, $\mathrm{P}=0.0003$, two-way ANOVA), suggesting the occurrence of an antagonist effect.

\section{Discussion}

$B C L 2$ is an important molecular target whose silencing has been attempted in tumors of different histological origin,

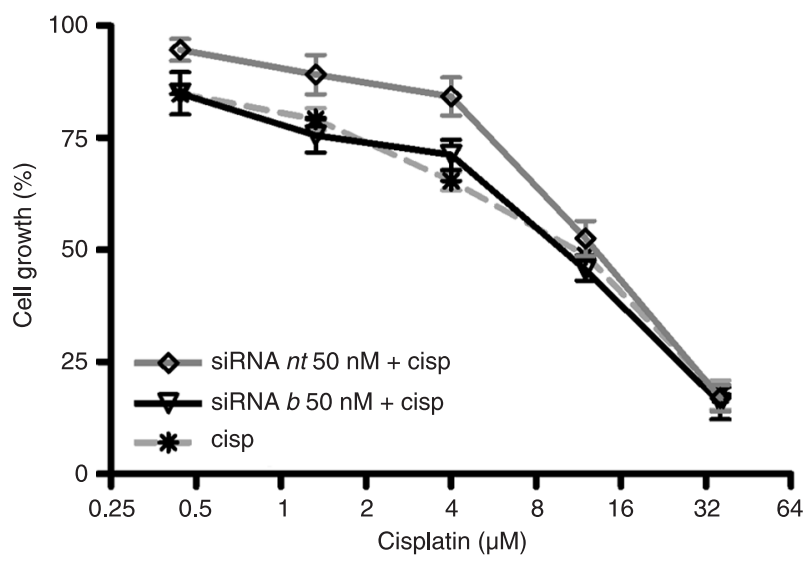

Figure 6. Effect of combined BCL2 silencing and treatment with cisplatin on the growth of SW2 small cell lung cancer cells. Tumor cells, untreated or treated with $50 \mathrm{nM}$ siRNA complexed with oligofectamine $(140 \mu \mathrm{L} / \mathrm{nmol}$ siRNA), were incubated with cisplatin $28 \mathrm{~h}$ after the first treatment, as described in Material and Methods. Cell growth was evaluated $96 \mathrm{~h}$ after the beginning of the experiment. siRNA = small interfering RNA. Each point represents the mean \pm SEM for $\mathrm{N}=3$ or 4 . Differences in the effect observed between siRNA $b$ and non-targeting (nt) sequences, combined with cisplatin (cisp) and between the latter combination and the single treatment with cisplatin were statistically significant $(P=0.0006$ and $P=0.0003$, respectively, twoway ANOVA). 
aiming at cancer treatment. The G3139 ODN has been one of the most relevant BCL2-silencing molecules tested, as illustrated by the promising results achieved in several clinical trials, notably in phase III trials against melanoma and chronic lymphocytic leukemia $(12,13)$. Another phase III trial (AGENDA trial) was recently initiated in patients with advanced melanoma. Mechanistically, however, the G3139 ODN has revealed significant effects unrelated to $\mathrm{Bcl}-2$. Its in vitro cytotoxicity to PC3 prostate cancer cells is independent of Bcl-2 down-regulation and correlates with the expression of stress inducible genes $(14,15)$. In melanoma cells, it triggers cytochrome c release from mitochondria and apoptosis, presumably by interacting directly with a mitochondrial channel (voltage-dependent anion selective channel, VDAC) (16).

The application of anti-BCL2 siRNA for therapeutic purposes has never been tested in SCLC. In the present study, it was demonstrated that the best siRNA sequence tested (sequence $b$ ) provided a high absolute value of mean $B C L 2$ silencing under optimized conditions (Figure 2C). However, despite multiple treatments and protein evaluation at different times post-treatment, BCL2 silencing analyzed in bulk SW2 SCLC cells did not go beyond 50 and $70 \%$ for the $\mathrm{Bcl}-2$ protein knockdown and mRNA level reduction, respectively (Figures $2 A$ and 5 ). Silencing was in fact potent ( $80 \%$ of protein knockdown, approximately) and heterogeneous (Figure $2 \mathrm{~B}$ and $\mathrm{C}$ ). This result correlates with the reduced fraction of successfully targeted cells, as assessed in the present study with FITC-labeled nucleic acid, and in agreement with the low transfection efficiencies previously reported for SCLC cell lines $(17,18)$. It is important to note that, in a previous report, transfection of SW2 cells with anti-survivin siRNAassociated with oligofectamine led to the same level of protein down-regulation (50\%) (19). Besides heterogeneous transfection, an additional reason that could justify the absence of a full protein (Bcl-2) knockdown is its high stability (reviewed in Ref. 20). In the present study, the use of flow cytometry analysis provided an opportunity to gain insights for the first time into $\mathrm{Bcl}-2$ down-regulation at the single-SCLC cell level upon treatment with siRNA simultaneously with cell viability.

Surprisingly, it was possible to observe an increase in the $\mathrm{Bcl}-2$ protein signal in viable cells after treatment with ODN (Figure 1C) and siRNA (Figures 2A and 3B) control sequences, an effect likely caused by oligofectamine. Its manufacturers do recommend the use of ODN concentrations of $200 \mathrm{nM}$ and alert to the occurrence of nonspecific effects at higher concentrations. This indication is consistent with the observed nonspecific cytotoxic effects within the range of $400-800 \mathrm{mM}$ for ODN (Figure 1B). It is important to emphasize that at the mRNA level, and in contrast to that observed with the protein, there was a sequence-specific increase in down-regulation when the dose of G3139 ODN was increased from 200 to $400 \mathrm{nM}$ (Figure 5). These results provide evidence that the observed nonspecific increase of $\mathrm{Bcl}-2$ protein is probably due to a post-translational effect, and could account for the lower Bcl-2 down-regulation compared to the corresponding mRNA.

The most important aspect emerging from the present study was that the down-regulation of Bcl-2 with ODN or siRNA did not result in a sequence-specific decrease in viability or in inhibition of cell growth (Figure 4), or in sensitization of tumor cells to cisplatin treatment (Figure 6 ). Intriguingly, the most efficient conditions for promoting $\mathrm{Bcl}-2$ down-regulation resulted in a higher cell viability than the corresponding treatment with siRNA nt (Figure 4A). In contrast, there was a similar activity in terms of cell growth under all tested conditions (Figure 4B). Since proliferation and viability are parameters that directly contribute to the overall cell growth of any cell population, the previousmentioned observations imply that proliferation should be reduced in siRNA $b$-treated cells compared to siRNA $n t-$ treated cells. These observations may be due either to the strong Bcl-2 silencing, revealing an alternative function of $\mathrm{Bcl}-2$ to the currently described anti-apoptotic one, or to the off-target effects derived from the siRNA sequence itself. Although the latter hypothesis cannot be excluded, there is evidence in the literature supporting the former. The notion that $\mathrm{Bcl}-2$ is a multifunctional protein, rather than being merely anti-apoptotic, is gaining strength. In distinct cell contexts, Bcl-2 has been reported to interfere with a wide variety of biological processes. In SCLC, there is evidence of Bcl-2 interaction with c-Myc in the cell nucleus and in the outer mitochondrial membrane, enhancing c-Myc half-life (21). c-Myc is a protein that has a positive effect on tumor cell proliferation, whereas upon a toxic stress to the cell, such as transfection in the present study, it can decrease tumor cell viability $(22,23)$. Thus, it can be hypothesized that, upon transfection, Bcl-2 silencing by siRNA $b$ leads to a decrease in the levels of c-Myc, causing a reduction in cell proliferation and an increase in cell viability (as compared to siRNA $n t$ ).

The present in vitro observations seem to contradict existing expectations regarding the impact of BCL2 on the viability of SCLC cells, namely raised from its role in hematological malignancies and from reports involving the use of anti-BCL2 ODN in SW2, H69 and H82 SCLC cells (8). However, the contribution of the in vivo environment should also be considered, since it may determine a different role for $\mathrm{Bcl}-2$. This was the case in melanoma, where in vitro drug-induced cytotoxicity and resistance were independent of $\mathrm{Bcl}-2$, but stable $\mathrm{Bcl}-2$ silencing reduced the in vivo tumorigenic potential of melanoma cells $(24,25)$. Nevertheless, despite controversial data, existing evidence about the specific role of Bcl-2 in SCLC is consistent with the results obtained in the present study. It has been demonstrated that, regardless of the frequently observed $\mathrm{Bcl}-2$ overexpression in SCLC cell lines (2) and tumors (3), there is no correlation between $\mathrm{Bcl}-2$ expression and resistance to therapy and/or patient survival (26-30). In fact, Bcl-2 
overexpression, mainly with nuclear localization, together with a high $\mathrm{Bcl}-2 / \mathrm{Bax}$ ratio, was correlated directly with an elevated spontaneous apoptosis index (31-33), and with the absence of metastasis in SCLC tumors (34). The relationship between $\mathrm{Bcl}-2$ overexpression and tumor stage is less clear, but an inverse correlation between Bcl-2 levels and cancer progression has already been pointed out (29,34-36). In addition, there are cases of reduced $\mathrm{Bcl}-2$ levels upon in vitro acquisition of resistance to cisplatin (37). Overall, it is not surprising that an immunosilent derivative of G3139 ODN did not reveal any therapeutic activity when tested in a murine model of human SCLC (38).

With the development of small molecules capable of inhibiting anti-apoptotic $\mathrm{Bcl}-2$ family proteins, BCL2 regained a new protagonism (39). Results from studies with these inhibitors support the idea that in order to achieve a deleterious effect on SCLC cells it will be necessary to interfere with more than one of the $\mathrm{Bcl}-2$ family proteins. In fact, the Bcl-2 family inhibitor ABT-737 is effective against some SCLC lines by simultaneously inhibiting three antiapoptotic proteins (Bcl-2, Bcl-xL, and $\mathrm{Bcl}-\mathrm{w})$. In addition, in the case of the expression of a fourth anti-apoptotic protein (Mcl-1), its knockdown is further required to achieve increased tumor cell death, thus reinforcing the importance of a multitargeted approach (40).

Gene silencing represents an opportunity to change the treatment paradigm of many diseases. With such strategy it is theoretically possible to inhibit any molecular target within a cell, as opposed to what happens with small molecular weight drugs or protein therapeutics. The present study, which reports for the first time the effect of anti-BCL2

\section{References}

1. Ries LA, Melbert D, Krapcho M, Stinchcomb DG, Howlader $\mathrm{N}$, Horner MJ, et al. SEER cancer statistics review (19752005). http://seer.cancer.gov/csr/1975_2005/.

2. Ikegaki N, Katsumata M, Minna J, Tsujimoto Y. Expression of bcl-2 in small cell lung carcinoma cells. Cancer Res 1994; 54: 6-8.

3. Ben-Ezra JM, Kornstein MJ, Grimes MM, Krystal G. Small cell carcinomas of the lung express the $\mathrm{Bcl}-2$ protein. $\mathrm{Am} \mathrm{J}$ Pathol 1994; 145: 1036-1040.

4. Reed JC, Cuddy M, Slabiak T, Croce CM, Nowell PC. Oncogenic potential of bcl-2 demonstrated by gene transfer. Nature 1988; 336: 259-261.

5. Hockenbery D, Nunez G, Milliman C, Schreiber RD, Korsmeyer SJ. Bcl-2 is an inner mitochondrial membrane protein that blocks programmed cell death. Nature 1990; 348: 334336.

6. Rudin CM, Kozloff M, Hoffman PC, Edelman MJ, Karnauskas R, Tomek R, et al. Phase I study of G3139, a bcl-2 antisense oligonucleotide, combined with carboplatin and etoposide in patients with small-cell lung cancer. J Clin Oncol 2004; 22: 1110-1117.

7. Rudin CM, Salgia R, Wang X, Hodgson LD, Masters GA,
siRNAs on SCLC, benefited from single-cell analysis. Among the sequences tested, siRNA $b$ significantly downregulated $\mathrm{Bcl}-2$ in a sequence-specific manner both at the protein and mRNA levels. Surprisingly, Bcl-2 knockdown was heterogeneous at the individual cell level and did not translate into a specific decrease of cell viability, specific inhibition of cell growth or chemosensitization to cisplatin treatments. These results raise questions about the in vitro (anti-apoptotic) role of Bcl-2 in SCLC claimed in previous reports, and support the growing notion of the necessity of a molecular multitargeting approach, especially when considering anti-apoptotic strategies, in the fight against cancer.

\section{Acknowledgments}

The authors wish to acknowledge Liliana Mendonça, from Center for Neuroscience and Cell Biology, Coimbra, for helpful discussions, including technical advice in real-time PCR. A.O. Santos was the recipient of a fellowship from the Portuguese Foundation for Science and Technology (FCT; ref.: SFRH/BD/11817/2003). Research supported by a Portuguese grant from FCT, POCTI, and FEDER (ref.: POCTI/FCB/48487/2002) and by the Portugal-Spain capacitation program in nanoscience and nanotechnology (NANO/NMed-AT/0042/2007). Cisplatin was kindly provided by Drs. Angelina Esteves Martins and Odete Isabel (from the Pharmacy of the University Hospital of Coimbra) and the use of the PCR detection system/iCycler ${ }^{\circledR}$ Thermal Cycler was kindly facilitated by Prof. A.B. Sarmento-Ribeiro, from the Faculty of Medicine, University of Coimbra.
Green M, et al. Randomized phase II Study of carboplatin and etoposide with or without the bcl-2 antisense oligonucleotide oblimersen for extensive-stage small-cell lung cancer: CALGB 30103. J Clin Oncol 2008; 26: 870-876.

8. Ziegler A, Luedke GH, Fabbro D, Altmann KH, Stahel RA, Zangemeister-Wittke $U$. Induction of apoptosis in small-cell lung cancer cells by an antisense oligodeoxynucleotide targeting the $\mathrm{Bcl}-2$ coding sequence. J Natl Cancer Inst 1997; 89: 1027-1036.

9. Zangemeister-Wittke U, Schenker T, Luedke GH, Stahel RA. Synergistic cytotoxicity of bcl-2 antisense oligodeoxynucleotides and etoposide, doxorubicin and cisplatin on small-cell lung cancer cell lines. Br J Cancer 1998; 78: 1035-1042.

10. Santos A, Sarmento-Ribeiro AB, de Lima MC, Simoes $S$, Moreira JN. Simultaneous evaluation of viability and Bcl-2 in small-cell lung cancer. Cytometry A 2008; 73A: 1165-1172.

11. Pfaffl MW. A new mathematical model for relative quantification in real-tiem RT-PCR. Nucleic Acids Res 2001; 29: 2002-2007.

12. Bedikian AY, Millward M, Pehamberger H, Conry R, Gore $\mathrm{M}$, Trefzer $\mathrm{U}$, et al. Bcl-2 antisense (oblimersen sodium) plus dacarbazine in patients with advanced melanoma: the 
Oblimersen Melanoma Study Group. J Clin Oncol 2006; 24: 4738-4745.

13. O'Brien S, Moore JO, Boyd TE, Larratt LM, Skotnicki A, Koziner B, et al. Randomized phase III trial of fludarabine plus cyclophosphamide with or without oblimersen sodium (Bcl-2 antisense) in patients with relapsed or refractory chronic lymphocytic leukemia. J Clin Oncol 2007; 25: 11141120.

14. Raffo A, Lai JC, Stein CA, Miller P, Scaringe S, Khvorova A, et al. Antisense RNA down-regulation of bcl-2 expression in DU145 prostate cancer cells does not diminish the cytostatic effects of G3139 (Oblimersen). Clin Cancer Res 2004; 10: 3195-3206.

15. Anderson EM, Miller P, Ilsley D, Marshall W, Khvorova A, Stein CA, et al. Gene profiling study of G3139- and Bcl2-targeting siRNAs identifies a unique G3139 molecular signature. Cancer Gene Ther 2006; 13: 406-414.

16. Lai JC, Tan W, Benimetskaya L, Miller P, Colombini M, Stein CA. A pharmacologic target of G3139 in melanoma cells may be the mitochondrial VDAC. Proc Natl Acad Sci U S A 2006; 103: 7494-7499.

17. Salon C, Merdzhanova G, Brambilla C, Brambilla E, Gazzeri S, Eymin B. E2F-1, Skp2 and cyclin E oncoproteins are upregulated and directly correlated in high-grade neuroendocrine lung tumors. Oncogene 2007; 26: 6927-6936.

18. Roelle S, Grosse R, Buech T, Chubanov V, Gudermann T. Essential role of Pyk2 and Src kinase activation in neuropeptide-induced proliferation of small cell lung cancer cells. Oncogene 2008; 27: 1737-1748.

19. Belyanskaya LL, Hopkins-Donaldson S, Kurtz S, SimoesWust AP, Yousefi S, Simon HU, et al. Cisplatin activates Akt in small cell lung cancer cells and attenuates apoptosis by survivin upregulation. Int J Cancer 2005; 117: 755-763.

20. Reed JC. A day in the life of the Bcl-2 protein: does the turnover rate of $\mathrm{Bcl}-2$ serve as a biological clock for cellular lifespan regulation? Leuk Res 1996; 20: 109-111.

21. Jin Z, Gao F, Flagg T, Deng X. Tobacco-specific nitrosamine 4-(methylnitrosamino)-1-(3-pyridyl)-1-butanone promotes functional cooperation of $\mathrm{Bcl} 2$ and c-Myc through phosphorylation in regulating cell survival and proliferation. J Biol Chem 2004; 279: 40209-40219.

22. Supino R, Perego P, Gatti L, Caserini C, Leonetti C, Colantuono $\mathrm{M}$, et al. A role for C-myc in DNA damage-induced apoptosis in a human TP53-mutant small-cell lung cancer cell line. Eur J Cancer 2001; 37: 2247-2256.

23. Kim YH, Girard L, Giacomini CP, Wang P, Hernandez-Boussard T, Tibshirani R, et al. Combined microarray analysis of small cell lung cancer reveals altered apoptotic balance and distinct expression signatures of MYC family gene amplification. Oncogene 2006; 25: 130-138.

24. Benimetskaya L, Lai JC, Khvorova A, Wu S, Hua E, Miller P, et al. Relative $\mathrm{Bcl}-2$ independence of drug-induced cytotoxicity and resistance in 518A2 melanoma cells. Clin Cancer Res 2004; 10: 8371-8379.

25. Benimetskaya L, Ayyanar K, Kornblum N, Castanotto D, Rossi J, Wu S, et al. Bcl-2 protein in 518A2 melanoma cells in vivo and in vitro. Clin Cancer Res 2006; 12: 4940-4948.
26. Kaiser U, Schilli M, Haag U, Neumann K, Kreipe H, Kogan E, et al. Expression of bcl-2 - protein in small cell lung cancer. Lung Cancer 1996; 15: 31-40.

27. Takayama K, Ogata K, Nakanishi Y, Yatsunami J, Kawasaki M, Hara N. Bcl-2 expression as a predictor of chemosensitivities and survival in small cell lung cancer. Cancer $J$ Sci Am 1996; 2: 212-216.

28. Maitra A, Amirkhan RH, Saboorian MH, Frawley WH, Ashfaq $R$. Survival in small cell lung carcinoma is independent of Bcl-2 expression. Hum Pathol 1999; 30: 712-717.

29. Paik KH, Park YH, Ryoo BY, Yang SH, Lee JC, Kim CH, et al. Prognostic value of immunohistochemical staining of p53, bcl-2, and Ki-67 in small cell lung cancer. J Korean Med Sci 2006; $21: 35-39$

30. Lee HW, Han JH, Kim JH, Lee MH, Jeong SH, Kang SY, et al. Expression of excision repair cross-complementation group 1 protein predicts poor outcome in patients with small cell lung cancer. Lung Cancer 2008; 59: 95-104.

31. Sirzen F, Zhivotovsky B, Nilsson A, Bergh J, Lewensohn R. Higher spontaneous apoptotic index in small cell compared with non-small cell lung carcinoma cell lines; lack of correlation with Bcl-2/Bax. Lung Cancer 1998; 22: 1-13.

32. Soini Y, Paakko P, Lehto VP. Histopathological evaluation of apoptosis in cancer. Am J Pathol 1998; 153: 1041-1053.

33. Joseph B, Ekedahl J, Sirzen F, Lewensohn R, Zhivotovsky $B$. Differences in expression of pro-caspases in small cell and non-small cell lung carcinoma. Biochem Biophys Res Commun 1999; 262: 381-387.

34. Pal'tsev MA, Demura SA, Kogan EA, Jaques G, Zende B. Role of Bcl-2, Bax, and Bak in spontaneous apoptosis and proliferation in neuroendocrine lung tumors: immunohistochemical study. Bull Exp Biol Med 2000; 130: 697-700.

35. Zereu M, Vinholes JJ, Zettler CG. p53 and Bcl-2 protein expression and its relationship with prognosis in small-cell lung cancer. Clin Lung Cancer 2003; 4: 298-302.

36. Abdulkader I, Sanchez L, Cameselle-Teijeiro J, Gude F, Chavez JE, Lopez-Lopez R, et al. Cell-cycle-associated markers and clinical outcome in human epithelial cancers: a tissue microarray study. Oncol Rep 2005; 14: 1527-1531.

37. Kumar Biswas S, Huang J, Persaud S, Basu A. Downregulation of $\mathrm{Bcl}-2$ is associated with cisplatin resistance in human small cell lung cancer $\mathrm{H} 69$ cells. Mol Cancer Ther 2004; 3: 327-334.

38. Gekeler V, Gimmnich P, Hofmann HP, Grebe C, Rommele M, Leja A, et al. G3139 and other CpG-containing immunostimulatory phosphorothioate oligodeoxynucleotides are potent suppressors of the growth of human tumor xenografts in nude mice. Oligonucleotides 2006; 16: 83-93.

39. Oltersdorf T, Elmore SW, Shoemaker AR, Armstrong RC, Augeri DJ, Belli BA, et al. An inhibitor of $\mathrm{Bcl}-2$ family proteins induces regression of solid tumours. Nature 2005; 435: 677681.

40. Lin X, Morgan-Lappe S, Huang X, Li L, Zakula DM, Vernetti $L A$, et al. 'Seed' analysis of off-target siRNAs reveals an essential role of $\mathrm{Mcl}-1$ in resistance to the small-molecule Bcl-2/Bcl-XL inhibitor ABT-737. Oncogene 2007; 26: 39723979. 